\title{
Drug safety provisions in US and Europe outshine Canada
}

Published at www.cmaj.ca on Nov. 5

$\mathrm{N}$ ew approaches to drug safety are yielding dividends in the United States and Europe, while legislation to introduce tougher new regulations in Canada continue to languish, delegates to the seventh annual Canadian Drug Information Association conference in Ottawa, Ontario, were told Nov. 4.

The US Food and Drug Administration (FDA) "is moving aggressively. Drug safety is moving to the next level, methodology is changing rapidly and enforcement is a high priority," said Dr. Barton Cobert, president of BLCMD Associates LLC, a drug safety consulting firm.

For example, drug companies that fail to report adverse events can and have - faced charges under the False Claims Act, Barton said, noting that the legislation also allows bona fide whistleblowers to be rewarded with payments with as much as $25 \%$ of the financial damages collected from companies.

The US and the European Union introduced risk management approaches to drug safety in 2005. Canada uses the European template for risk evaluation and mitigation strategies, but regulators can only issue guidance in cases where there is noncompliance, said Kimby Barton, cochair of Health Canada's Health Portfolio Risk Management Planning Working Group.

The long-awaited overhaul of Canada's Food and Drug Act, which would have introduced a "life cycle" approach to pharmaceutical monitoring, died on the order paper in Parliament before the last election and has not yet been reintroduced, Barton said. Health Canada's powers to enforce key safety provisions once a drug is on the market are thus very limited.

In the US, amendments to the Food and Drug Administration Act in 2007 were "game changing," Cobert told the more than 250 representatives from gov-

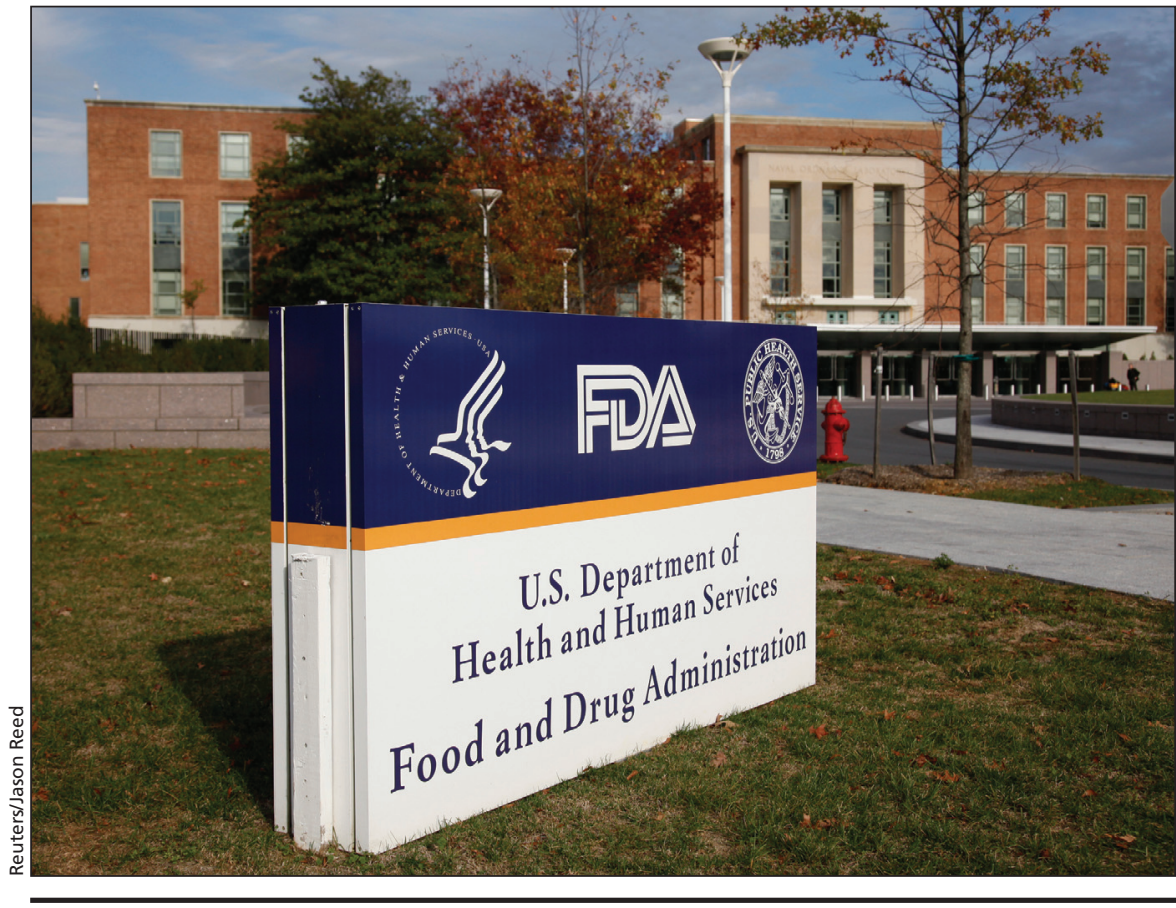

The headquarters of the US Food and Drug Administration in Silver Spring, Maryland. The FDA is taking drug safety "to the next level," drug safety expert Dr. Barton Cobert says.

ernment, industry and patient advocacy groups.

The amendments, which included revisions to the Prescription Drug User Fee Act, gave the FDA the teeth needed to compel companies to conduct postmarket studies, patient registries and clinical trials, Cobert added. Furthermore, the FDA can make post-market studies a requirement for new drug applications to be approved.

Post-market study requirements, which "previously were lax," now have fixed time frames and are enforceable, Cobert said, adding that the FDA has provided its field employees with procedures on how to enforce post-market requirements.

The FDA can also now force label changes and require risk evaluation and mitigation strategies for both newly approved drugs, as well as prescription drugs that have been marketed for years, such as opiods, he added.
Cobert also said that several new initiatives are being launched in the US to more actively monitor drug safety, including the Sentinel Initiative, a nationwide electronic monitoring system that aims to have data on 25 million patients by 2010. The initiative will include patient registry data, insurance claims data and other information obtained from health maintenance organizations or government programs such as Medicare, Medicaid and Veterans Health Administration programs.

The big effort to date has been to "normalize the data ... and set standards for coding," Cobert said.

Medicare, which covers health care costs for people over age 65 in the United States, is also introducing a safety surveillance system and developing tools to identify low-probability adverse events - the kind of risks that are not identified in premarket clinical trials or early post-marketing experiences, Cobart added. 
Another initiative includes expert reviews of the safety of new medical entities. A review of five relatively new drugs (they had been on the market 17 to 64 months) found 22 previously unidentified safety issues on four of the drugs, even though two were being used by fewer than 3500 patients, Cobert said.

Barton told the conference that risk management plans will be a key ele- ment in the life cycle approach to pharmaceuticals if, as expected, the Canadian legislation is reintroduced. Already, particularly with respect to new biologics, the regulator has asked for such plans, she said, noting that in fiscal year 2008/09, plans were requested for $67 \%$ (10 out of 15 ) of new drug submissions for biologics.

Because of differences in health care policies and legislation, risk management plans for one jurisdiction may not be applicable in another, Barton noted. Even in Canada, provincial jurisdiction over health care means that "if we suggest strategies for how doctors or pharmacists can prescribe, how will that fly?" - Ann Silversides, CMAJ

DOI:10.1503/cmaj.109-3102 